\section{Global Journal of Foreign Language Teaching}

Volume 07, Issue 1, (2017) 52-58

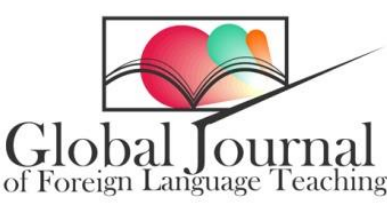

www.gjflt.eu

\title{
Learning style preferences of Persian learners: Case study of Arabic speakers
}

Ezzat Tabatabei *, Department of Applied Linguistics, Ferdowsi University of Mashhad, 9177948974, Mashhad, Iran

Mina Ghazi Joolae, Imam Reza International University, 91735-553, Mashhad, Iran

\section{Suggested Citation}

Tabatabei, E. \& Joolaee,M. G. (2017). Learning style preferences of Persian learners: Case study of Arabic speakers. Global Journal of Foreign Language Teaching. 7(1), 52-58.

Received September 16, 2016; revised November 23, 2016; accepted February 25, 2017

Selection and peer review under responsibility of Assoc. Prof Dr. Ali Rahimi, Bangkok University, Thailand. (C)2017 SciencePark Research, Organization \& Counseling. All rights reserved

\begin{abstract}
Learning styles refer to the strategies and processes that facilitate learning and understanding the concepts. So, teachers can incorporate their learning styles in their curriculum activities. It also, will help students to be more attracted to learning session and instantly give attention to the session undertaken by the teachers. The purpose of the experiment is to ascertain the learning styles of learners using the VARK questionnaire. This study is an analysis of learning style for 100 Iraqi and Syrian Persian learners completed a VARK questionnaire to determine if their learning styles are auditory, reading/writing, visual or kinesthetic. Out of 100 participants who responded the questionnaire, their preferred learning style was visual by 12 percentages, 16 auditory, 13 Reading/writing and 20 kinesthetic. According to data analyze, we provide implications for improving learning process.
\end{abstract}

Keywords: Learning styles VARK; visual, aural, reading/writing, kinesthetic, Arabic Persian learners.

*ADDRESS FOR CORRESPONDENCE: Ezzat Tabatabei, Department of Applied Linguistics, Ferdowsi University of Mashhad, 9177948974, Mashhad, Iran

E-mail address: ezat.tabatabaei@stu.um.ac.ir / Tel.: +98-9151237913 


\section{Introduction}

Learning is a process that everybody connects it, and this association is different in them. It is thought that learning ability of everyone is dependent on level of intelligence and talent. But in the last few years, psychologists express despite the determinative role of innate factors like intelligence and talent, other acquired factors are important.

After some extensive research, psychologist has concluded that how the learning process is more important than learning process. So choosing learning method is important and we cannot simply ignore it. Choosing learning methods have a high impact learning process. Learning style help us in how learning process. Also, each style needs a different method for teaching.

Leone believed that learning style is theorized that the way in which a person learns new and difficult information most efficiently requires the person to accommodate his or her own particular learning style strengths and preferences (Leone, 2008). In fact learning style refers to cognitive, emotional and psychological factors. They are as relatively stable characteristics that have a role in the way of comprehension, engagement and respond to environmental (Khazaei, 2006).

In other words, each student has his/her own learning style, and they learn better with their styles. Learning style affects their level of learning under special circumstances. For instance, some students learn best through listening, while others may learn best from visual displays. Therefore, it is necessary; teachers become acquainted with learning styles, and they should create a positive learning environment. If learners understood their own learning style, could promote different ways of learning. Therefore, it is important to consider students' learning styles and it is very important for teacher to share information with students about their learning styles and the preferred teaching strategies to accommodate those styles.

There are different ways to determine study styles; one of those is VARK learning style. Gardner (2008) express that the VARK focuses on how learners prefer to use their senses (hearing, seeing, writing, reading, or experiencing) to learn. The acronym VARK stands for "Visual", "Aural", Read/Write" and "Kinaesthetic". Visual learners prefer to learn information through charts, graphs, symbols, and other visual means. Aural learners prefer to hear information. Read/Write learners prefer to learn information that is displayed as words, and kinaesthetic learners prefer to learn through experience and practice, whether simulated or reality (Gardner, 2008). In fact, learners have a collection of styles that one of those is dominant. If they use more senses, learning becomes deeper.

In this study, we are supposed to show the dominant preference in learning styles of learners is Read/Write and most learners prefer single modal learning style.

\subsection{The importance of learning style in learning:}

As humans have different characteristics, psychological traits are different too. Because we have different behaviour, there are various ways of learning. Guild and Garger (1998) noted that learning style is a unique aspect of our humanity; it is the way we perceive the world and governs how we think, make judgments and form values about experiences and people. One effective way in deep learning is acquaintance with learning style, with due attention to different ways of learning. Sometimes learners have problems in learning process. Others believe that weakness shows they don't have ability in learning. While lack of ability is not the problem, there is something in learning style. The way of studying is not coordinate with their own learning style, or teaching style is not adapted to the way of learning. So learners get tired and their effort is ineffective. Also, Sims points the importance of learning style. For the student who has been unsuccessful with previous teaching style, learning is a misery and there is little chance that in the next course or class the student will suddenly adjust his or her learning style or even be capable of adjusting (Sims, 1995, p.8). Therefore, learners and teachers should know about learning style to increase quality of learning and teaching.

Guild and Garger (1998) noted that learning style is a unique aspect of our humanity; it is the way we perceive the world and governs how we think, make judgments and form values about experiences and people. 
Lack of coordination (relationship) between teacher's teaching style and the student's way of learning is one of the learning obstacles in class. This can be a reason for scheming and using a variety of teaching styles. As Lefever in his book states when teachers understand student's learning styles and adjust their teaching to those styles, students will learn (Lefever, 2011). If learners know about their personal learning style, they can gain power and control over their personal learning styles and the learning process. Teachers also have an opportunity to adapt to teaching method to the students' way of learning. So it causes a good output in learning process.

\section{Literature Review}

One of the most effective approaches in studying learning is learning styles. Theories in this field were developed in recent years. Studying learning style began in 1950s and early 1960s because of interesting in effect of individual difference in learning process. Until 1970s wide researches perform in this area, but after that it reduced. In the last two decades, the topic of learning styles has been interested more than pervious. Now learning style is one of the most important fields in learning area.

In a review of accomplished learning research in a 20 years period, learning style called an important factor in creating motivation and academic achievement. So researchers assess positive role of learning style in learning and academic achievement. Many studies strongly suggested that there are relationships between certain learning styles and students' effective achievements

Felder (1996) differentiates between learning styles as follows; "Students have different learning styles - characteristic strengths and preferences in the ways they take in and process information. Some students tend to focus on facts, data, and algorithms; others are more comfortable with theories and mathematical models. Some respond strongly to visual forms of information, like pictures, diagrams and schematics; others get more from verbal form- written and spoken explanation. Some prefer to learn actively and interactively; others function more introspectively and individually" $(p, 18)$.

A study by Hamouzade (2011) analyzed learning styles of Health Management students and used VARK questionnaire as material and SPSS software for analyzing data. The Results show that only $33 / 1 \%$ prefer one dominant preference out of 150 management students. $10 / 8 \%$ had the kinaesthetic preference, 10 had the read/write preference, $9 / 2 \%$ had the auditory preference and $3 / 1 \%$ had the visual preference. Almost students (66/9\%) prefer multimodal learning style $(18 / 5 \%$ bimodal, $13 / 1 \%$ trimodal, 35/4 multimodal). He concluded that awareness of teachers causes developing effective way of education and adaptive to students learning style.

Azadmanesh (2014) conducted a study among medical students and the result shows that there is a meaningful relation between gender, period of education and learning styles. Marital status has a significant relationship with read/write learning style. Also period of education has a significant relationship with kinaesthetic style. So, teacher awareness of variety learning style is so important. Because choosing suitable learning style causes effective learning.

An article "Gender and learning styles in Saudi Arabia schools" was printed by Saadi in 2014. The purpose of this study was to investigate the difference between males and females student in Saudi preparatory schools. A total cohort of 399 students from 8 schools in Jeddah city was responded to VARK questioner. The result indicated a significant relationship between gender and learning style (multimodal or single modal). However in VARK7G the result of showed there is no relationship between gender and learning style.

A study was also conducted among nursing students in Jordan public university to identify the learning style preferences of the respondents (Alkhasawneh, 2013). The Participants are 197 nursing students who were at different academic levels in Jordan University. $55 \%$ of students have a multimodal preference; about $60 \%$ of multimodal students have the kinaesthetic preference. Of the $45 \%$ students who have one dominant preference: $60 \%$ had the kinaesthetic preference as the dominant preference, and $40 \%$ had the auditory preference accompanied with another preference. The result shows that teachers at nursing program should use more than one teaching modality to be 
Tully, Dunn and Hlawaty (2006) conducted a study to determine whether teaching methods and learning material based on the identified learning style preferences of students is better than traditional teaching methods. The study showed that those who were taught based on their learning style preferences had better performances than those who were taught using traditional teaching methods.

A study conducted by Lincoln and Rademacher (2006) focused on the learning styles of adult English as second language (ESL) students in Northwest Arkansas using a VARK learning style model. A total of 69 students from 17 countries responded to a VARK questionnaire. The results showed that approximately one third of participants gravitated towards read/write as their favoured learning style. Of the remaining respondents, $20 \%$ preferred aural learning, $25 \%$ preferred kinaesthetic learning and $4 \%$ preferred visual learning. The remaining $17 \%$ preferred multiple mode learning.

A few studies have previously been performed using the VARK questionnaire in Iran, however this study particularly looks at the preferred learning styles of Persian language learners using the VARK questionnaire, for the first time.

\section{Methods and Data Analysis}

The participants of this study were 100 Persian learners studying at International centre for teaching Persian to non-Persian, Ferdowsi university of Mashhad, Iran. They were $10 \%$ Syrian and $90 \%$ Iraqi students between 22 and 54 years of old. This study has not focused on gender differences. All received the VARK Arabic version questionnaire. The majority of learners take 20 to 30 minutes to complete the questionnaire and the score is then calculated.

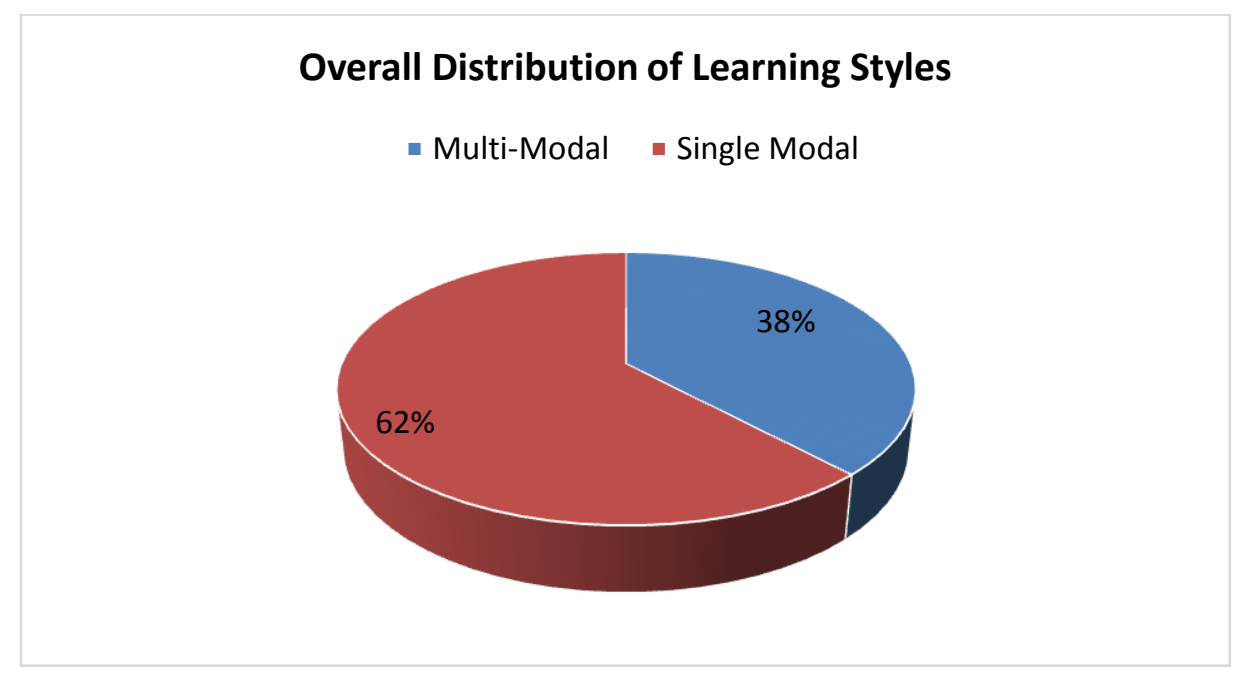

Figure1. Overall Distribution of Learning Styles of Learners

The data derived from the VARK was categorized according to their learning style in two groups: Multimedia style and single style. Descriptive statistical including percentage was calculated and shows preferred learning style according to visual, auditory, reading and writing and kinaesthetic style. 


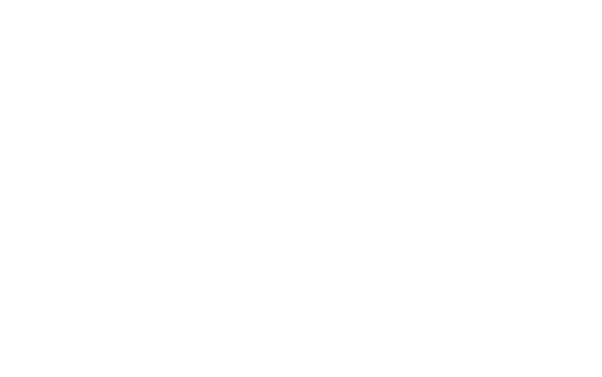

Figure2. Single Preference

Among 100 Participants, 62\% preferred single modal and 38\% preferred multimodal learning styles (Figure1). Multimodal learners can be more flexible about how they take in and give out information than those with a single learning preference or style. They tend to be able to match their preferences with whatever modes are being used. Therefore, if learners prefer single modal learning style, they may have problem in learning and classroom. Because a single preference learners would 'get it' from just their preferred mode - if it was available in the class and environment. Out of 100 learners, $12 \%$ chose visual style, $13 \%$ read/write style, $17 \%$ auditory and $20 \%$ kinaesthetic style (Figure 2). So the result shows that their preferred style is kinaesthetic. Despite of the result the observation shows that learners do vice versa and use reading/writing style in class, that's why they have problem in learning. Also, learners use less from visual sense Visual sense is very important sense in learning process. The brain absorbs the information and concept best when the information is delivered through visual sense.

\section{Pedagogical Implications}

As learning style is different, the way of teaching is different. There are some points according them:

\subsection{Visual learning style}

Visual learners learn best by viewing information presented in formats such as demonstrations, pictures, videos, and films, illustrated textbooks, flipcharts and everything more attractive. So, teacher should convert notes and translate words into symbols, diagrams, and picture. Limit amount of words and allows them for mental imagery. Visual stories are a good way to memorize information, and also use painting for better learning.

\subsection{Auditory learning style}

Auditory learners learn best through listening. It is better to be in groups or with a study partner. Ask them talking things through and listening to what others have to say. They check homework together and read the text and notes out loud. Also they interpret the underlying meanings of speech through listening to the voice tone, pitch, and speed.

\subsection{Read/Write learning style}

Read/Write learners prefer traditional way of learning like reading books, taking notes and review notes. Emphasize taking notes, because information displayed as words. It is so important they write with their own words. Also organize diagrams/graphs into statements. 
Tabatabei, E. \& Joolaee,M. G. (2017). Learning style preferences of Persian learners: Case study of Arabic speakers. Global Journal of Foreign Language Teaching. 7(1), 52-58.

\subsection{Kinesthetic learning style}

Kinaesthetic learners don't like the traditional way of learning. It is difficult for these learners to sit for long periods. It is better to use movement and hands-on approach, include as many examples in teaching. It is better to show concepts through examples, because it is essential for them. Also, it is good if teacher provide activities where learners can engage all senses when processing information.An additional recommendation is that the identification of the learning styles of learner has been put forward as a contributing factor in the development of learners' achievement but it is impossible to teach according to individual's learning styles. Therefore, teachers are to be able to use all four styles and the way of teaching is a combination of all styles.

\section{Discussion and Conclusion}

Every learner learns in a different way. Learning style varies from one group to another based on culture, the nature of the studies and the characteristics of students, so if it was possible to find out how each person learns then it would allow a teacher to present a class in a more structured way to facilitate the different ways in which learning is achieved. Equally, if a learner knows and understands how they best learn, then the subject lesson can be a more rewarding experience.

Result shows that kinaesthetic style $(20 \%)$ is dominant learning style between Arabic speakers who learn Persian language. kinaesthetic learners like to acquire their information through experience and practice in real environment. It is much better teachers use examples for each concept. But the observation shows that they do vice versa and use reading/writing style in class, that's why they have problem in learning.

Result shows that $16 \%$ of participants preferred to learn by the aural style. These learners prefer to attend lecture and group discussion.

The percentage of leaner with read/writing is $13 \%$. Read/write learners learn through reading and writing. As such, university style courses suit these types of learners fairly well-plenty of text books and study notes to read.

Finally, the minority style is visual style with only $12 \%$. Visual sense is very important sense in learning process. The brain absorbs the information and concept best when the information is delivered through visual sense. So if the learners use this sense less will affected on their learning. Visual learners should be stimulated with depictions of information in charts, graphs, flow charts, and all the symbolic and other devices that teacher use to represent what could have been presented in words.

Result shows there are $62 \%$ learners with a single modal and $38 \%$ preferred multimodal leaning style. Because learners prefer use one style for learning. Multimodal learners prefer to receive information by using different methods that's why, according observation, there are more successful than single modal learners.

According to results of this study, regarding different types of learning styles, learners need different methods to educate themselves and it is better for both teachers and learners to try different methods of educating. The combination of different approaches and teaching methods can make it possible for learners with all type of learning styles to be successful in learning.

\section{References}

AlKhasawneh, E. (2013). Using VARK to assess changes in learning preferences of nursing students at a public university in Jordan: Implications for teaching. Nurse Education Today, 33, 1546-1549

Azadmanesh, K. (2014). Learning Styles of First Year Nursing and Midwifery Students in Qazvin University of Medical Sciences Based on Vark Theories. Nursing Education, 2(3)

Felder, R. (1996) Mattters of style. ASEE Prism, 6(4), 18-23.

Gardner. J.(2008). Your College Experience: Strategies for Success. USA: Wadsworth Cengage Learning publisher.

Guild, P., \& Garger, S. (1998) Marching to different drummers (2nd, ed.). Alexandria, Virginia: Association for Supervision and Curriculum Development.

Khazaei, K. (2006). Learning Style. Nowshar: The Islamic Azad University, Nowshahr \& Chaloos branch

Lefever, M. (2011). Learning styles. USA David C Cook publisher.

Leone, C. (2008). Effects of more-versus less congruent parental-child learning styles on the vocabulary achievement, comprehension and attitudes of fourth through sixth - grade students involved in a 
Tabatabei, E. \& Joolaee,M. G. (2017). Learning style preferences of Persian learners: Case study of Arabic speakers. Global Journal of Foreign Language Teaching. 7(1), 52-58.

homework support process (Doctoral dissertation). Available from ProQuest Dissertation and theses databases. (UMI No: 3340428).

Lincoln, F., \& Rademacher, B. (2006). Learning styles of ESL students in community colleges'. Community Journal of Research and Practice, 30(5), 485-500. Dio: 10.1080/10668920500207965

Saadi, I. A. (2014). Gender and learning styles in Saudi Arabia schools. In Volume the Clute Institute International Academic Conference, San Antonio, Texas, USA: Saudi Arabia: King Abdulaziz University (pp. 159-68).

Tully. D., Dunn, R., \& Hlawaty, H. (2006). Effects of programmed learning sequences on the mathematics tesr scores of Bermudian middle school students. RMLE Online Research in Middle Level Education, 30(2) 111. 